\title{
Social and quality attributes influencing consumption of native poultry in eastern Uganda
}

\author{
James. Higenyi $^{1}$, John. David. Kabasa ${ }^{1}$, Charles. Muyanja ${ }^{2}$ \\ ${ }^{1}$ College of Veterinary Medicine, Animal Resources and Bio-security, Makerere University, Kampala, Uganda \\ ${ }^{2}$ College of Agriculture and Environmental Sciences, Makerere University, Kampala, Uganda

\section{Email address:} \\ higenyijames9@gmail.com (J. Higenyi), jdkabasa@yahoo.com (J. D. Kabasa), ckmuyanja@yahoo.co.uk (C. Muyanja)
}

\section{To cite this article:}

James. Higenyi, John. David. Kabasa, Charles. Muyanja. Social and Quality Attributes Influencing Consumption of Native Poultry in Eastern Uganda. Animal and Veterinary Sciences. Vol. 2, No. 2, 2014, pp. 42-48. doi: 10.11648/j.avs.20140202.15

\begin{abstract}
Poultry consumers in Uganda are increasingly interested in consumption of native chicken compared to duck and turkey meat. By far the most important driving force for selective consumption is preference. The aim of this study was to determine the factors that influence preference for consumption of native poultry in Butaleja and Tororo districts. A field survey of rural and peri-urban poultry consumers and food service providers was conducted through semi-structured interviews using questionnaires; and a total of 195 respondents were covered. The assessment parameters included: socio-economic factors, acceptability, purchase and consumption preference criteria, aversion reasons, choice and frequency of consumption and limitations. The results of survey revealed high acceptability of all native poultry meat types $80.35 \%$. The main economic activity of consumers was non-salary employment $71.3 \%$. The most significant $(\mathrm{p}<0.001)$ attributes that guided consumer purchasing behaviour and consumption were eating quality attributes $26.26 \%$, product availability $26.74 \%$ and product size $50.62 \%$. In addition, consumption preference for duck meat was very significantly $(\mathrm{p}<0.05)$ associated with location, tribe and religion. The use of the poultry products by food service providers was dependent on customer preference $65 \%$ and price $71.4 \%$. The main reasons for aversion to use and consume the turkey and duck meat were: perception of sanitary conditions $44 \%$ and product unavailability $21.9 \%$. Consumers frequently ate chicken 1 to 2 times $55.8 \%$ in a month and none at all for duck and turkey meat $73.7 \%$. The main significant $(\mathrm{p}<0.001)$ limitations to frequency of consumption were product unavailability $57.32 \%$ and market price $42.51 \%$. Consumer concerns of good health $52.8 \%$ and sensory quality $61.1 \%$ influenced their choices to buy and eat prepared poultry form. In conclusion, socio-economic factors, perception of quality cues and quality attributes influence purchasing and consumption preference. Therefore, sensitization campaigns on nutritional quality, modern production and value addition is necessary.
\end{abstract}

Keywords: Native Poultry Meat, Quality Attributes, Consumption Preference, Value Addition, Socio-Economic Factors

\section{Introduction}

Native poultry meat is a cheap source of protein and household income particularly to the poor rural and peri-urban families in developing countries [4, 9]. World over, the growing demographic trend is anticipated to increase demand of foods of animal source, especially poultry meat [9]. Apparently consumers in Uganda are increasingly interested in native chicken than ducks and turkeys [27]. Native poultry meat significantly contributes $80 \%$ of total poultry meat in the market trend which represents $1.62 \mathrm{~kg}$ supplying $187 \mathrm{grams}$ of protein per person per year $(0.5 \mathrm{gm} /$ person/day) [6]. However, native chicken meat is increasingly becoming expensive, which, in turn has constrained the demand and consumption by the poorer rural families. For instance, consumption of native chicken in rural families is $7 \%$ compared to $80 \%$ in urban and peri-urban families $[8,18]$. Moreover, about quarter of the rural population in Uganda suffer from malnutrition and greater percentage is dietary micronutrient defiencency even though livestock resources are projected to increase at rate of $4 \%$ per annum [26]. It is acknowledged that food of animal origin is rich in micronutrients and the decreasing level of consumption in the rural communities increases malnutrition problems [3]. Among the main challenges to consumption of native poultry is limited demand attributed to consumers' preference. Contemporary information emphasizes that individual preference may be driven by cultural, socio-economic factors and religious factors [2, 5, 11]. In addition, it was observed that differences in 
individual preference, demographs and culture are more important determinant of consumption levels in societies than the economic factors [13]. Equally more important is the consumer preference for quality attributes and or values of their products [22]. In the context of this research, the concept of quality is defined as the product's value or the extent to which a product contributes to the economic goals or as the composite of all product attributes which yield consumer satisfaction while quality attributes denote those bundles of quality features of the product perceived as important by the consumer for example sensory attributes, safety, price, availability, convenience extra [15]. This implies the quality product that meets or satisfies needs or expectations of the consumer. As such the product performance will influence the individual preferences, desirability and acceptability of the product. Of the quality attributes, sensory attributes are more important in determining acceptability of poultry product as well as influencing the consumption [5]. Literature re-affirms that consumer preference for native chicken to exotic chicken is influenced by increased perception of quality values such as suitability for special dishes, taste and flavour and their pigmentation [8]. Although turkey and duck meat is globally accepted as human food, in Uganda they are decreasingly utilized due to little interest in their products and limited demand [4, 7, 26]. Moreover, most researchers that have conducted studies in traditional poultry production and development, have proposed integration of turkeys and ducks production with chicken in rural communities in developing countries $[5,10,20]$. The recommendations are based on excellent nutritional benefits such as proteins, B-vitamins and Iron from duck and turkey meat [1, 5]. As such, they are potential alternative sources of cheap animal proteins particularly in the poorer rural and semi-urban communities. Promoting consumption of native poultry particularly ducks and turkey is one way of reducing on the micronutrient deficiency prevalent in rural regions of the country. In this respect therefore, understanding the social factors and quality attributes that influence consumer preference is important. This study was conducted to determine acceptability, frequency of consumption of native poultry meat especially duck and turkey meat by the peri-urban consumers. Further, establish the social and quality attributes of native poultry that influence choices and intake.

\section{Materials and Methods}

The study design to data collection involved quantitative approaches. The survey method was used to collect data using valid questionnaires administered to randomly selected respondents through semi-structured interview. A total of 195 respondents (172 poultry meat consumers and 23 restaurant owners) were interviewed. Raw data capturing and cleaning was done in EpiData version 3.1soft ware, after which was exported to STATA/SE version 11 software for analysis. Descriptive analysis to represent frequencies and percentages was carried out using the software. Chi-square was used to establish the link between predictors and consumption of native poultry meat using bivariate analysis.

\section{Result: Field Survey of Consumers}

The descriptive summaries of the socio-demographic characteristics of poultry meat consumers were: Majority respondents interviewed were male $71.5 \%(n=123)$, most of whom fell between age of 30-39 years represented by $44.8 \%$ $(n=77)$. There were nine ethnic groups representing the respondents; Adhola 40.7\% $(n=70)$ and Munyole $45.9 \%$ $(n=79)$ were predominant. The religion of respondents in the two districts was dominated by Catholic 34.3\% $(n=59)$ and Anglican $46.5 \%(n=80)$. The level of education for the respondents varied from primary, 'O'level, high school, diploma, degree and post graduate, but majority were primary $29.1 \%(n=48)$ and 'O'level $28.5 \%(n=47)$. The predominant economic activity for the respondents was non-salary employment $71.3 \%(n=123)$. The consumption of native poultry meat by location, tribe and religion was only significant for duck $(\mathrm{p}<0.05)$. The results also shows high acceptability poultry meat types represented by rating respondents' consumption; chicken $99.4 \%(\mathrm{n}=171)$, turkey 93.6\% $(\mathrm{n}=162)$ and duck $80.4 \%(\mathrm{n}=139)$. Most respondents showed that chicken was most preferred and desired $89.5 \%$ $(n=153)$ followed by turkey $80.9 \% \quad(n=131)$ and least preference for duck $81.3 \%(\mathrm{n}=113)$ as represented in fig1.

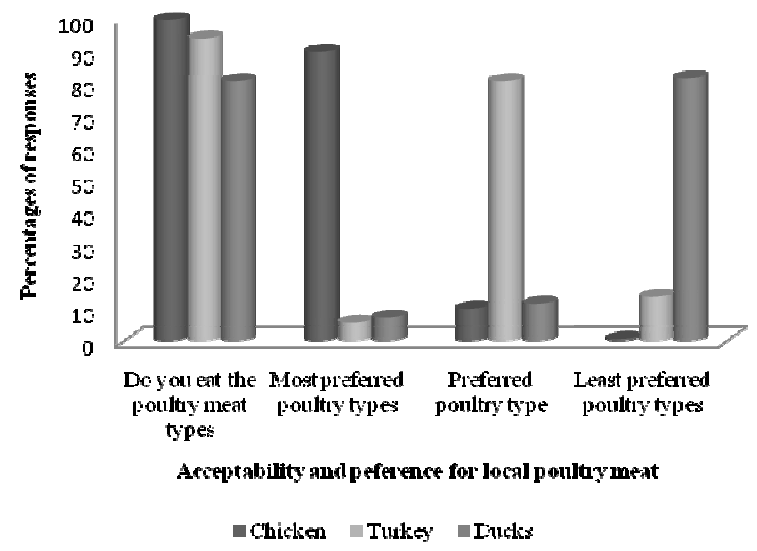

Figure 1. Consumer acceptability and preference for native poultry meat.

The restaurants' willingness to use the poultry types was highest for chicken than others as presented by rating respondents use; chicken $100 \%(n=23)$, turkey $60.9 \%(n=14)$ and duck $21.8 \%(n=5)$. In addition preference rating for use in restaurants was: most preferred chicken $91.3 \%(\mathrm{n}=21)$, followed by turkey $59.1 \%(n=13)$ and least preferred duck $81.0 \%(\mathrm{n}=17)$. Statistically preference rating was significant $(\mathrm{p}<0.05)$ both to consumption and use. The important preference criteria considered by consumers while purchasing the native poultry meat types were: perception of sensory quality $26.3 \%(n=45)$, product availability $26.7 \%$ $(n=46)$, perception of nutritional quality $22.1 \%(n=38)$ and 
biological factors $11.6 \%(n=20)$; price $27.2 \%(n=44)$, product size $50.6 \%(\mathrm{n}=82)$ and biological factors $7.4 \%$ $(n=12)$; perception of benefits $25.9 \% \quad(n=36)$, product availability $23.7 \%(n=33)$ and product familiarity $15.8 \%$ $(\mathrm{n}=22)$ for chicken, turkey and ducks respectively (table1).

Table 1. Important preference criteria for purchase of the native poultry meat type.

\begin{tabular}{llll}
\hline Variable & $\begin{array}{l}\text { Chicken } \\
(\mathbf{n , ~ \% )}\end{array}$ & $\begin{array}{l}\text { Turkey } \\
(\mathbf{n , ~ \% )}\end{array}$ & $\begin{array}{l}\text { Ducks } \\
(\mathbf{n , \%},\end{array}$ \\
\hline Perception of sensory quality & $45(26.2)$ & $9(5.6)$ & $10(7.2)$ \\
Biological and production factor & $20(11.6)$ & $12(7.4)$ & $9(6.5)$ \\
Convenience of preparation & $4(2.3)$ & $2(1.2)$ & $14(10.0)$ \\
Product availability & $46(26.7)$ & $2(1.2)$ & $33(23.7)$ \\
Price (cost of product) & $6(3.5)$ & $44(27.2)$ & $6(4.3)$ \\
Cultural and ceremonial & $3(1.7)$ & $0(0.0)$ & $0(0.0)$ \\
Social status and prestige & $0(0.0)$ & $0(0.0)$ & $3(2.2)$ \\
Product size/weight & $9(5.2)$ & $82(50.6)$ & $4(2.9)$ \\
Income status of consumer & $0(0.0)$ & $1(0.6)$ & $1(0.7)$ \\
Perception of nutritional quality & $38(22.1)$ & $6(3.7)$ & $36(25.9)$ \\
Product familiarity(experience) & $1(0.6)$ & $4(2.5)$ & $22(15.8)$ \\
\hline
\end{tabular}

These preference criteria were significant to the consumption of the native poultry meat $(p<0.001)$. The most important factors influencing preference to use of native poultry for restaurants were; customer preference $65.2 \%$ $(\mathrm{n}=15)$, market price $71.4 \%(\mathrm{n}=10)$ and product availability $60 \%(n=3)$ for chicken, turkey and ducks respectively. Preference for use of native poultry meat in restaurants was statistically significant ( $\mathrm{p}=0.008)$ particularly duck meat.

The most important reasons for aversion to consume duck meat were; perception of untidiness $44 \% \quad(n=33)$, inconvenience in processing methods $21.1 \%(\mathrm{n}=28)$, beliefs $16.9 \%(n=25)$ and unavailability of product $21.9 \%(n=26)$ and turkey meat; perception of untidiness $22.8 \%(n=18)$, inconvenience in slaughtering and processing methods $16 \%$ $(n=16)$, beliefs $16.9 \%(n=25)$ and unfamiliarity $20 \%(n=26)$ as presented in (fig.2). These were very significant $(\mathrm{p}<0.001)$ for duck meat consumption. The respondents for restaurants presented unavailability of product $100 \%(\mathrm{n}=2)$ and was statistically insignificant $(\mathrm{p}=0.269)$. Furthermore, restaurants respondents reported that dislike of sensory quality attributes of products by consumer influence use of native poultry meat. Other reasons for non-consumption of native poultry in restaurants were dislike of sensory quality attributes such as: mealness $87.5 \%(\mathrm{n}=28)$, toughness $73.3 \%$ $(n=110)$ and smell of raw meat $83.6 \%(n=122)$ for chicken, turkey and duck respectively.

Meat quality attributes were perceived significant preference criterion for consumption and use of native poultry meat. The three most important eating quality attributes included: taste $70.6 \%(\mathrm{n}=121)$ and texture $14.5 \%$ $(n=25)$; taste $70.9 \%(n=115)$ and texture $11.1 \%(n=18)$; taste $63.3 \%(n=88)$ and flavour $13.7 \%(n=19)$ for chicken, turkey and ducks respectively; and were very significant $(\mathrm{p}<0.001)$. The food providers reported important sensory quality attributes that influence customer preference for native poultry meat as: taste $39.1 \%(n=9)$ and flavour $43.5 \%$ $(\mathrm{n}=10)$; taste $28.6 \%(\mathrm{n}=4)$ and flavour $42.9 \%(\mathrm{n}=6)$; taste $20 \%(n=1)$ and flavour $40 \%(n=2)$ for chicken, turkey and duck respectively. The most important eating quality attributes are as shown in fig. 3 .

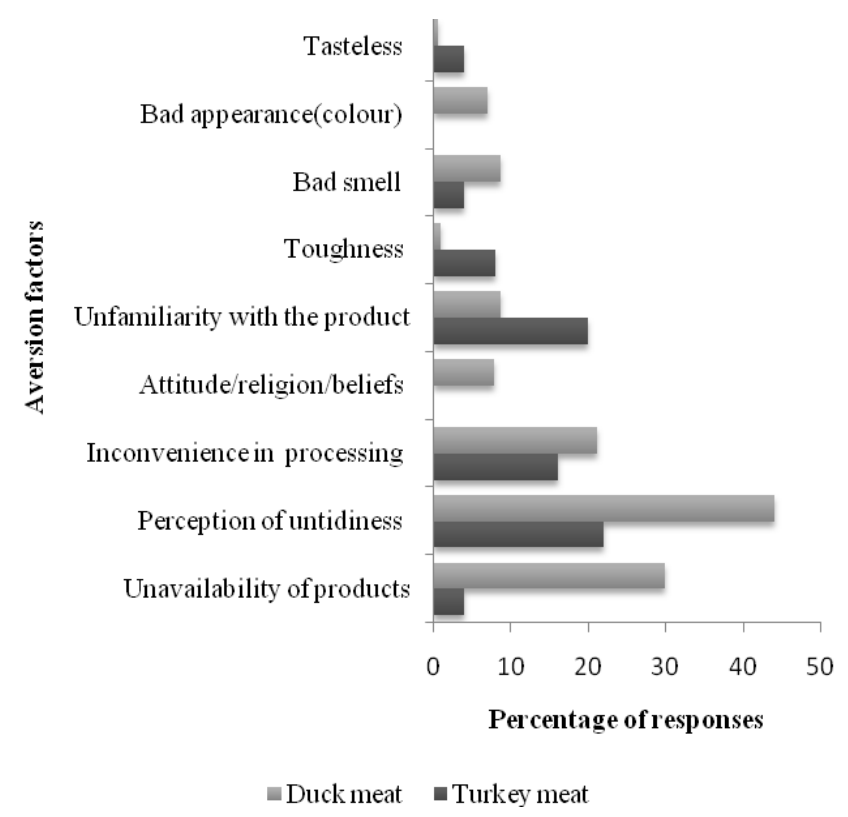

Figure 2. Important reasons for aversion to consume and use of turkey and duck meat.

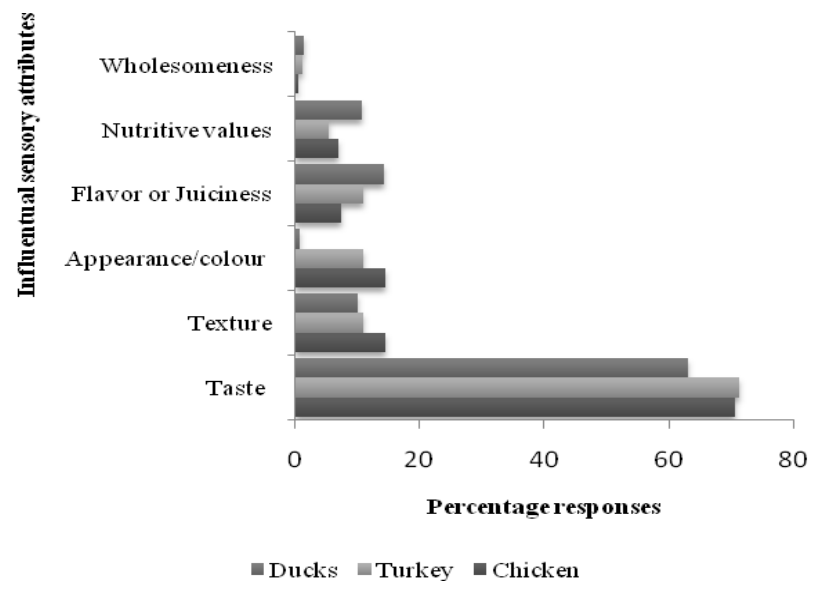

Figure 3. Sensory quality attributes and cues affecting consumption preference for native poultry meat.

The most significant biological attributes considered while purchasing native poultry were: welfare and health $37.8 \%(n=65)$, diet $30.2 \%(n=52)$ and sex of bird $14.0 \%$ $(n=24)$; age of bird $58.0 \%(n=94)$, cooking methods $18.5 \%$ $(\mathrm{n}=30)$ and diet $6.2 \%(\mathrm{n}=10)$; processing $71.2 \%(\mathrm{n}=99)$, age of birds $13.7 \%(n=19)$ and cooking methods $4.3 \%(n=6)$ for chicken, turkey and ducks respectively (fig.4). These biological attributes were statistically insignificant $(p>0.05)$ to consumption and use. The frequency of consumption of traditionally prepared poultry products in a month was rated as: native chicken meat more frequently consumed $55.8 \%$ $(\mathrm{n}=96)$ compared to duck meat $4.1 \%(\mathrm{n}=1)$ and turkey meat $1.2 \%(n=2)$ (fig. 5$)$. 
The main challenges associated with the above frequency of consumption were: product availability $55.6 \%(n=95)$, product unavailability $57.3 \% \quad(\mathrm{n}=94)$ and market price $42.5 \%(n=71)$ for chicken, duck and turkey respectively. These are very significant $(\mathrm{p}<0.001)$ to the consumption of native poultry meat. Though, income status of consumer $9.4 \%(n=16)$ and perception of quality $21.1 \%(n=36)$ were also important in for chicken consumption while attitude $18.3 \%(\mathrm{n}=30)$ for duck consumption. These challenges are represented in table 2 .

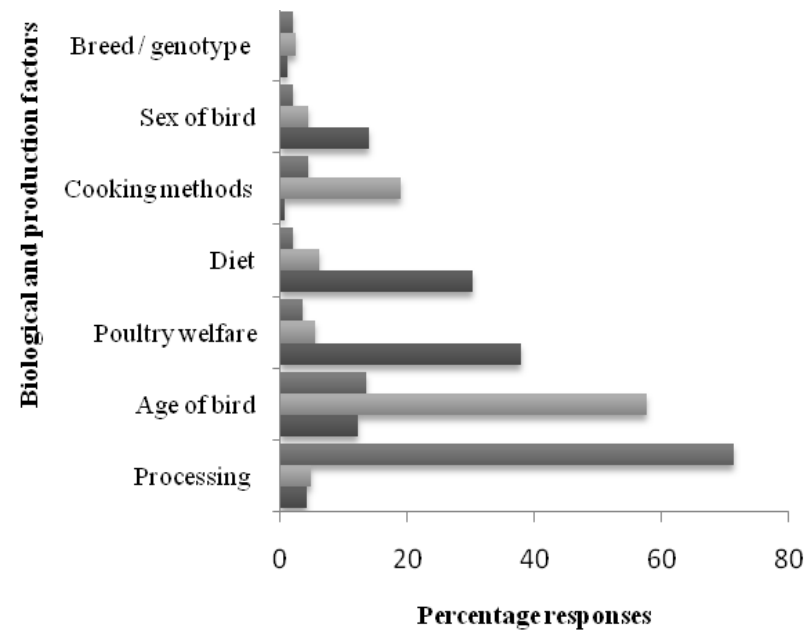

Ducks $=$ Turkey $\square$ Chicken

Figure 4. Important biological and production factors.

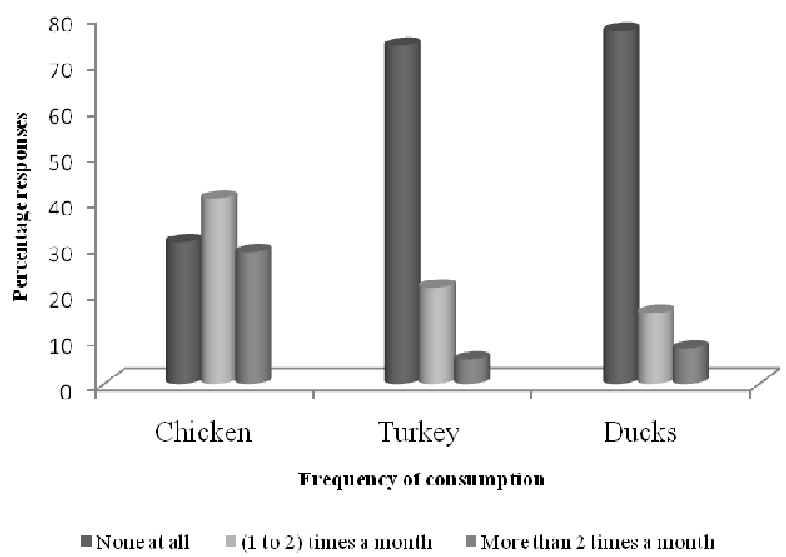

Figure 5. Frequency of consumption of traditional poultry products in a month.

The most preferred prepared form of traditional poultry products by consumers were: smoked-boiled for turkey $66.1 \%(\mathrm{n}=107)$ and ducks $84.7 \%(\mathrm{n}=61)$ and stew for chicken $55.6 \% \quad(n=95)$. The results further show that consumption preference criterion for prepared forms and portion (smoked-boiled and stew) was attributed to perception of importance of good health and perception of sensory evaluation. This was represented by respondents as: 36. $6 \%(\mathrm{n}=63)$ and $61.1 \%(\mathrm{n}=105) ; 52.8 \%(\mathrm{n}=86)$ and $45.4 \%$ $(n=74), 53.3 \%(n=73)$ and $44.5 \%(n=61)$ for chicken, turkey and ducks respectively (fig.6).
Table 2. Factors influencing frequency of consumption of native poultry meat.

\begin{tabular}{llll}
\hline Variables & $\begin{array}{l}\text { Chicken } \\
(\mathbf{n}, \%)\end{array}$ & $\begin{array}{l}\text { Turkey } \\
(\mathbf{n}, \%)\end{array}$ & $\begin{array}{l}\text { Duck } \\
(\mathbf{n}, \%)\end{array}$ \\
\hline Product availability & $95(55.6)$ & $0(0.0)$ & $24(14.6)$ \\
Income status of consumer & $16(9.4)$ & $13(7.8)$ & $5(3.1)$ \\
Market price & $2(1.1)$ & $71(42.5)$ & $3(1.8)$ \\
Perception of sensory quality & $36(21.1)$ & $1(0.6)$ & $2(1.2)$ \\
Unfamiliarity with processing & $0(0.0)$ & $3(1.8)$ & $5(3.0)$ \\
Attitude / beliefs & $0(0.0)$ & $4(2.4)$ & $30(18.3)$ \\
Culture/religion & $0(0.0)$ & $0(0.0)$ & $1(0.6)$ \\
Ceremonial/ festive & $5(2.9)$ & $5(3.0)$ & $0(0.0)$ \\
Product unavailability & $17(10.0)$ & $70(41.9$ & $94(57.3)$ \\
\hline
\end{tabular}

The limitations to restaurant use of poultry meat types were: product unavailability $42.1 \% \quad(n=8)$, lack of knowledge and skills to slaughter $31.6 \% \quad(n=5)$ and consumer preference $26.3 \%(n=5)$; product unavailability $22.7 \%(\mathrm{n}=5)$, high price $50(\mathrm{n}=11)$ and income status of proprietors $18.2 \%(n=4)$; consumer preference $47.8(n=11)$, product unavailability $30.4(\mathrm{n}=7)$ and high price $8.7 \%(\mathrm{n}=2)$ for duck, turkey and chicken respectively. The restaurants viewed live bird as the most preferred purchase form of the product for chicken $100 \%(n=23)$ and duck $100 \%(n=5)$ while cut-ups was desired for turkey $57.1 \%(n=8)$. The strongest reasons for that preferred purchase form was increased interest in biological factors and price.

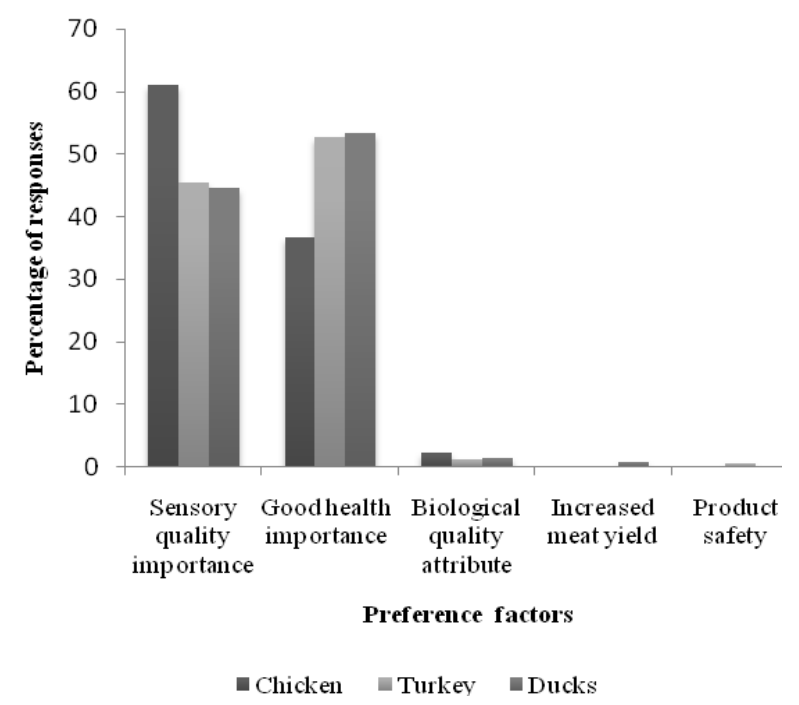

Figure 6. Important consumption preference criteria for prepared forms and portions.

\section{Discussion}

Interestingly, this present study has revealed that majority of respondents in the sampled districts consume native chicken, turkey and duck meat. As such, they are highly acceptable in our poor rural and peri-urban societies with chicken being the most preferred local poultry type. This is much in observance of other studies [2, 3, 17]. This empirical result suggests that native poultry types continue to contribute significantly to the increasing nutritional 
demands of the poorer rural and peri-urban families. More importantly, the results showed that socio-economic factors, consumer interest and perception of product quality attribute influence preference for consumption and use of native poultry products. This emphasizes that fact hat consumption is influenced by multifactorial factors [23]. Focusing on socio-demographic characteristics, location, tribe and religion were very significant ( $p$-value $<0.05)$ determinants of consumer preference especially for duck meat. This is an indication that location either per-urban or rural, tribe or religious beliefs influence consumer behaviour and preference for intake of duck meat. This concurs with other studies [4, 11]. Interestingly however, age of respondents, education and occupation were not considered significant in influencing consumption of native poultry meat. This finding is strongly consistent with the fact that no matter the level of education attained by the consumers, beliefs and preferences remain unchanged [24]. The level of education and gender the consumer was found to hardly influence preference and consumption [16]. This suggests that improved production of native poultry products could be appropriate intervention to micronutrient deficiency both in the poorer peri-urban and rural families.

Regarding individual preference criterion, respondents differed on most significant reasons for their preference while purchasing. Consumers considered economic factors (availability and price), nutritional benefits and perception of eating quality attributes as more important determinants of preference for purchasing and consumption of native poultry meat. Other factors included: ease preparation (convenience), biological and production factors, product familiarity and socio-cultural reasons. Similarly restaurants considered customer preference and economic factors as more important determinants of native poultry meat usage. These results were observed to be consistent with the fact that economic filters such as price, income status of the consumer and product availability influence actual consumption rather than reflecting the real consumer preference $[14,15]$. This is equally true in respect to the study areas because they are considered socio-economically poor districts [6]. Thus, in case the commodity price/cost is high, economic status of the consumer won't allow easy purchase of the good. Though, could be of his preference. As such, for peri-urban and rural consumers, economic factors are more important determinants what they buy to eat but not what they prefer. On contrary, preference, demographics, differences in culture and tastes were increasingly deterministic of consumption levels than the differences in income/ price and product availability [13]. Of the eating quality attributes the most important as presented by consumers were: taste, texture and flavour of the products. Though, taste was highly rated by the majority of the interviewed respondents. In another study, this finding was consistently emphasized [22]. It was further observed that biological and production factors similarly influence consumers' decision to purchase the local poultry meat for consumption and use. The most important biological and production factors rated by consumers and restaurant users included: processing/preparation methods, age of bird, welfare and health which ultimately influence the eating quality attributes of the product. This further justifies the observed consumer preference for purchase of live form of the product. This was in agreement with the research findings of other studies $[12,19]$.

Focusing on cultural factors, the results revealed that ceremonial or tradition aspects, attitude and beliefs appear to influence consumption preference and use of native poultry meat to a lesser magnitude. The later determinants are probably explained by the fact that attitude is formed by beliefs people have about certain aspects of poultry products. Thus, influencing habits, behavour and practices with in lifestyle, which, in turn determine the consumption behaviour. The results are very much in support of a report emphasizing the fact that cultural differences was more important determinants of consumption levels in societies $[11,13]$. Other factors that were revealed to influence consumption included: product unavailability, unfamiliarity and processing factors. These drivers that limit consumption of local poultry meat were particularly very significant to duck meat. This is strongly in support of the contemporary research on duck meat consumption in other countries [20, 21].

Focusing on frequency of consumption for traditionally prepared poultry products per months, the present results showed that majority of respondents more often (1 to 2 times a month) consumed chicken while consumption of duck and turkey meat was too low or none at all. Actually this was not surprising reflecting on the limitations to consumption namely: product unavailability and perception of eating quality attributes for chicken, price and product unavailability for turkey, product unavailability and attitude for ducks. The frequency of consumption was also observed to be limited by availability, price of product and cultural differences [11]. Other factors such as quality, price and income of the consumers influenced consumption and use of the food [15]. Despite the chicken meat being used on daily basis by most of restaurants, duck and turkey meat was more often used weekly. This finding contradicts another study which reported non-consumption and use of duck meat in rural communities due cultural orientations [7]. This study suggests existing social and cultural dynamics and particularly in this era of globalization, socio-economic changes are increasingly occurring in societies. And duck and turkey meat are increasingly becoming alternative sources of animal proteins. On the other hand, the most preferred prepared forms were: smoked-boiled for turkey and ducks and stew for chicken. And thigh and breast body parts are much preferred by the consumers. Interestingly however, the consumer preference for the prepared forms and body parts was mainly pegged to perception of nutritional quality which may include level of fat as parameter for health and perception of sensory quality. Though, product safety, biological factors and increased meat yield (product size) were also perceived relevant to 
consumers. In another study, this finding was equally emphasized [14]. In other words, results strongly suggest that consumers in rural and peri-urban areas are increasingly concerned with personal health and quality of the foods (products) consumed. As a consequence, their recurrent interest in better-quality food products. The health attitude and perception of eating quality attributes influence consumer behaviour, which in turn, impact on food preference and consumption. This finding is very much supportive of the current consumer behaviour and increasing trend in consumption of white meat than red meat globally. The growing need for animal proteins, health problems due to nutrition and consumers' awareness of food quality and safety issues have made the poultry sector a significant industry throughout the world $[16,21,28]$.

\section{Conclusions}

This study has established that socio- economic filters and attributes namely; product availability, product size and sensory attributes were more significant in influencing consumer purchasing behaviour and consumption of native poultry products. Consumers are increasingly making choices about prepared poultry forms based on eating quality attributes and health benefits of the products in respect to the levels of fat. Food providers can more significantly increase native poultry meat usage by responding to customer preference, price/cost and sensory quality attributes. Therefore, we recommend the following to improve the consumption of native poultry meat:

Encourage production of sausages for the neglected species because of the improved sensory attributes

Encourage modernization through education and belief updating

Increase on production and productivity of native poultry meat to avail the products easily and at affordable price.

\section{Acknowledgement}

The authors wish to thank the farmers and service providers from Butaleja and Tororo for their participation in the research. The study was funded by grant under the VASES program of the European Union.

\section{References}

[1] Adzitey, F. (2012). Production potential and the physicochemical composition of selected duck strains: A mini review. Online Journal of Animal and Feed Research, 2(1):89-94

[2] Asif, A.U., Khaskheli, M., Rajput, I.R., Rao, S., Faraz, S., Fazlani, S.A., Deurajani, K. and Umer, M. (2010). Examination of physical properties of goat meat. Pakistan Journal of Nutrition, 9 (5). 422-425

[3] FAO (2002). Global Production and Consumption of Animal Source Foods. Presented at the conference "Animal Source
Foods and Nutrition in Developing Countries" held in Washington, D.C.June 24-26.

[4] FAO (2003). Good practices in planning and management of intergrated commercial poultry production in Southern Asia. FAO Animal Production and Health Paper 159.

[5] FAO (2004). Small-scale poultry production. Technical guide, edited by E.B.Sonaiya \& S.E.J.Swan.Rome.ISSN 1810-1119

[6] FAO (2008). Poultry Sector Country Review. Uganda. FAO Animal Production and Health Division www.fao.org/avianflu//en/farmingsystems.html. Accessed on $6 / 3 / 2012$

[7] FAO (2009). The State of Food and Agriculture. http://www.fao.org/catalog/inter-e.htm. Accessed on 21/5/2012.

[8] FAO (2009b). The role of poultry in peoples livelihoods in Uganda. Prepared by state, A.E., Birungi,P.B., Haan,N..Rome: AHBL-Promoting Strategies for Prevention and Control of HPAI. http://www.fao.org/docrep/013/a1690e/a1690e00.pdf. Accessed 6/10/2013.

[9] FAO (2010). Poultry Meat and Eggs, agribusiness hand book. www.eastagri.org. Accessed on 4/3/2012.

[10] FAOSTAT (2009). Top production indigenous poultry meat. http://faostat.fao.org. Accessed on 5/12/2011. Fletcher, D.L. (2002). Poultry meat quality. World's poultry Science Journal 58(2):131-145. Doi:10.1079/WPS20020013

[11] Gossard, M.H. \& York, R. (2003). Social Structural influence on meat consumption. Human Ecology Review, 10(1):1-9

[12] Groom, G.M. (1990). Factors affecting poultry meat quality. CIHEAM- Options Mediterranneennes; 206-209 Science Journal, 65:116

[13] Herrmann, R. \& Roder, C. (1995). Does food consumption converge internationally? Measurement, empirical tests and determinants. European Review of Agricultural Economics, 22(3): 400-414.

[14] Huang, K.S. (1998). How Economic Factors Influence the Nutrient Content of Diet. Prepared for presentation at the 1998 American Agricultural Economics Association Annual meeting in the Salt Lake City.

[15] Kerry, J., Kerry, J., and Ledward, D. (2002).Meat processing, Improving quality. Woodhead Publishing Limited and CRC Press LLC. www.woodhead.publishing.com

[16] Kyarisiima, C.C., Nagajja, F.A., Magala, H., Kwezera, H., Kugonza, D.R. and Bonabana, J.W. (2011). Percieved tastes and preferences of chicken meat in Uganda. Livestock Research for Rural Development 23 (11).

[17] Kusina, J.F. \& Kusina, N.T. (1999). Feasibility study of agricultural and household activities as they relate to livestock production in Guruve District of Mashonaland Province with emphasis on poultry production. Report for the Household Agricultural Support Programme (HASP),Zimbabwe, sepetmber 1999.

[18] Mugga, R. (2006).Ugandan industry thriving, Word Poultry.22, 8 
[19] Northcutt, J. K. (2009). Factors Affecting Poultry Meat Quality.

http://www.thepoultrysite.com/articles/1312/factors-affectin g-poultry-meat-quality.Accessed on /9/2012

[20] Nurul. H., Ooi.J.L., Yong.C.P. and Tina.N. (2010). Effect of Chicken and Duck Meat Ratio on the Properties of Sausages. International Journal of Poultry Science, 9(6).550-555.

[21] Oteku, I., Igene, J.I. and Yessuf, I.M. (2006). An Assessment of the Factors Influencing the Consumption of Duck Meat in Southern Nigeria. Pakistan Journal of Nutrition,5(5).474-477.

[22] Santiago, A. (2002). Biological, Nutritional, and Processing Factors Affecting Breast Meat Quality of Broilers.

[23] Stern, P. C., Dietz, T., Ruttan, V. W., Socolow, R. H. and Sweeney, J. L.(1997b). Consumption as a problem for environmental science. In P.C. Stern, T. Dietz, V. W. Ruttan, R.H. Socolow and J. L. Sweeney (eds.). Environmentally Significant Consumption: Research Directions, 1-11. Washington, D.C: National Academy Press.

[24] Taylor, C., Dodd, T. and Barber, N. (2008). Impact of wine education on developing knowledge and preferences: An exploratory study. Journal of Wine Research, 19(3): 193-207

[25] UBOS (2009). Uganda Bureau of Statistics report 2009. Kampala, Uganda. Unpublished report.

[26] UBOS (2010). Statistical abstract, 2010. Uganda Bureau of Statistics. Kampala, Uganda.

[27] USAID (2010). Parternership for Safe poultry in Kenya (PSPK) Program. Value chain analysis of poultry in Uganda.

[28] Waskar, V.S., Devangare, A.A.1., Gosavi, P.P.1., Ravikanth, K.2., Maini, S.2.and Rekhe, D.S. (2009). Meat Quality Attributes of broilers supplemented with Herbal Toxin binder Product. Veterinary World, 2 (7): 274-277

[29] WHO (2001) .World Health Organisation surveillance programme for control of foodborne infections and intoxications in Europe. Seventh report, 1993-1998. In: Schmidt K. and Tirado C. (Ed). Federal Institute for Health Protection of Consumers and Veterinary Medicine (BgVV), Berlin, Germany, pp. 415, 422-423. 